\title{
Evaluación de productos botánicos para manejo de mosca blanca (Bemisia tabaci Gennadius) y pulga del tomate (Halticu ssp) en el cultivo de tomate (Solanum lycopersicum Mill.), en Nicaragua
}

\section{Evaluation of botanical insecticides to control whitefly (Bemisia tabaci Gennadius) and tomato flee (Halticu ssp) in tomato (Solanum lycopersicum Mill.), in Nicaragua}

\author{
Edgardo Jiménez-Martínez ${ }^{1}$, Harlem Tania Ríos-Peralta², Oscar Alejandro Somarriba-Moncada² \\ ${ }^{1}$ Facultad de Agronomía, ${ }^{2}$ Graduados de la carrera de Ingeniería Agronómica, Facultad de Agronomía. Para correspondencia: \\ edgardo.jimenez8@gmail.com, 505-2263-2609, Universidad Nacional Agraria
}

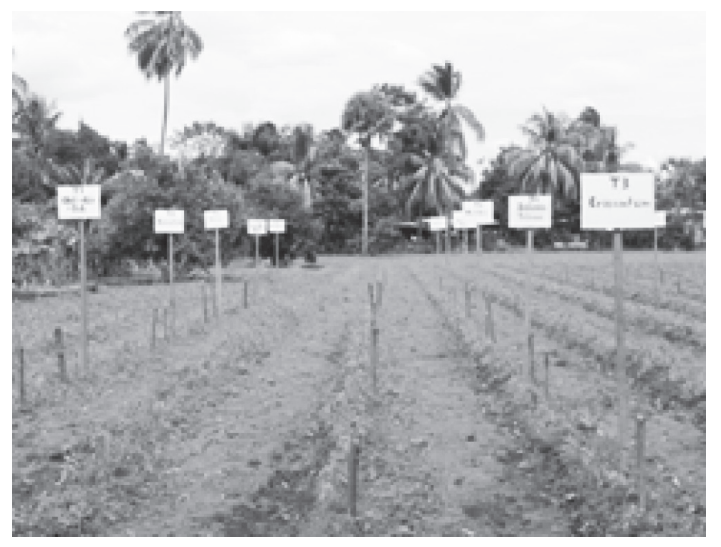

\section{RESUMEN}

El complejo mosca blanca (Bemisia tabaci)-Geminivirus y Halticus sp son las principales plagas causantes de pérdidas económicas en el cultivo de tomate (Solanum lycopersicum Mill) en el municipio de Tisma-Masaya. En base a esta situación se realizó un estudio para evaluar la efectividad que tiene para controlar estas y otras plagas secundarias los tratamientos botánicos: chile + ajo + jabón, madero negro, crisantemo, extracto alcohólico + chile, extracto alcohólico + chile + ajo y testigo en el período comprendido entre diciembre 2013 a febrero 2014. De los tratamientos evaluados, el menor número de moscas blancas por planta y el menor porcentaje de severidad a los cien después de trasplante lo obtuvo el tratamiento extracto alcohólico + chile + ajo. El tratamiento madero negro presentó la mayor efectividad en el manejo de poblaciones de Halticus sp. El mayor rendimiento se obtuvo con extracto alcohólico + chile + ajo con $34685.18 \mathrm{~kg} \mathrm{ha}^{-1}$ seguido del tratamiento chile + ajo + jabón con $30614.28 \mathrm{~kg} \mathrm{ha}^{-1}$. De acuerdo al análisis de tasa de retorno marginal, el tratamiento chile+ajo+jabón es el que obtuvo la mejor tasa de retorno marginal con $1476 \%$, es decir, USD 14.76 por cada dólar invertido. Además el análisis de biotipo de mosca blanca realizado en la Universidad de Tucson, Arizona muestra que un $66.66 \%$ corresponde a la mosca blanca autóctona (biotipo A), y el 33.33\% corresponde al biotipo B, el cual es más agresivo que el A. Según el análisis de los begomovirus se determinó: enrollamiento severo de la hoja de tomate (ToSLCV) con al menos $96 \%$ de identidad en las muestras y el virus del mosaico dorado de la chiltoma (PepGMV) con un $98 \%$ de identidad.

Palabras clave: begomovirus, insectos, insecticidas.

\begin{abstract}
The whitefly-virus complex (Bemisia tabaci)-Geminivirus and Halticus sp. are the main cause of economic losses in tomato (Solanum Lycopersicum Mill) in the municipality of Tisma, Masaya. Due to this situation, a study was conducted to evaluate the effectiveness of botanical insecticides such as: Chile + Garlic + Soap, Madero Negro, Chrysanthemum, alcoholic extract + Chili and alcoholic extract + Chili + Garlic in the period from December 2013 to February 2014. Of the treatments evaluated, the lowest number of whiteflies per plant and lower percentage of severity at one hundred days after transplanting was obtained with the treatment Alcoholic extract+Chili+Garlic. The treatment Madero Negro had the highest effectiveness in managing populations of Halticus sp. The economic analysis showed that the highest yield was obtained by the Alcoholic extract+Chili+Garlic with 34685.18 $\mathrm{kg} / \mathrm{ha}^{-1}$ followed by the treatment Chili + Garlic + Soap with 30614.28 $\mathrm{kg} / \mathrm{ha}^{-1}$. According to the marginal return analysis, this proved that the treatment Chili+Garlic+Soap is the one who obtained the best marginal rate of return with $1476 \%$, which means that USD 14.76 is obtained for every dollar invested. According to samples of tomato tissue and whiteflies insect samples sent for analysis to at the University of Arizona in Tucson, this determined that the $66.66 \%$ of white flies samples from Tisma are indigenous whitefly, biotype "A", and the $33.33 \%$ corresponds to the "B" biotype, the one that is more aggressive than " $\mathrm{A}$ ". The Begomoviruses analysis found that severe curl leaf tomato (ToSLCV) with at least $96 \%$ and golden mosaic virus of pepper (PepGMV) with 98\% identity were identified in this study.

Keywords: Begomovirus, insect, pesticides.
\end{abstract}


$\mathrm{E}$ 1 tomate pertenece a la familia de las solanáceas, es una planta perenne de porte arbustivo que se cultiva como anual. Puede desarrollarse de forma rastrera, semi-erecta o erecta. Existen variedades de crecimiento limitado (determinadas) y otras de crecimiento ilimitado (indeterminadas). El tomate es cultivado tanto en huertos caseros como en áreas comerciales, es una de las hortalizas más populares del mundo; es fuente de vitaminas A y C, y puede ayudar a corregir las deficiencias de esas vitaminas en países como el nuestro (INTA, 2004).

El tomate se siembra de forma estacional y responde a expectativas de precios por parte de los productores y a la disponibilidad de área con suficiente agua. Los rendimientos dependen del nivel de tecnología aplicado por los productores, así como de factores climáticos y fitosanitarios (CATIE, 1990). Las principales áreas de producción de tomate en Nicaragua están ubicadas en los departamentos de Matagalpa y Jinotega, particularmente en el valle de Sébaco y Tomatoya. Además se produce en zonas de Estelí, Malacatoya, Tisma y Nandaime, aunque en menor escala. Existen además otras zonas con potencial como el valle de Jalapa, la meseta de Carazo y algunos valles premontanos de los departamentos de Boaco y Chontales (MIFIC, 2007).

Como todo rubro, el tomate presenta problemas fitosanitarios de plagas, los cuales causan una disminución en el rendimiento del cultivo, sumado esto con el uso indiscriminado de insecticidas, fungicidas y herbicidas, que provocan un alza en los costos de producción; así como perjuicio a la salud humana y contaminación al ambiente. Dos de los principales problemas en el municipio de Tisma ha sido el ataque severo del complejo mosca blanca $(B$. tabaci)-Geminivirus y Halticus sp mejor conocido en Tisma, Masaya como la pulga del tomate.

La mosca blanca es una plaga que posee una amplia plasticidad genética, por lo que ha desarrollado biotipos con mayor agresividad que la especie autóctona (biotipo A). El biotipo $\mathrm{B}$ es el que ha producido más pérdidas y daños en América Latina (Álvarez y Sánchez, 2014). Esta plaga causa daños directamente al cultivo por la transmisión de Geminivirus causante de la virosis del tomate, capaz de devastar por completo una área determinada de cultivo, siendo las etapas más críticas las primeras semanas después de la germinación (Jarquín, 2004).

En el caso de Halticus sp es un chinche pequeño de color negro cuyas patas traseras, un poco anchas, están adaptadas para saltar. Está presente en gran cantidad de cultivos, es un insecto succionador, es decir, tiene un estilete para succionar la savia de las plantas. El signo más visible consiste en puntos blancos en la láminar foliar, la cual reduce la capacidad fotosintética. Cuando hay una alta población se pueden observar hojas casi totalmente blancas (Richmond, 2012).

Con el propósito de buscar alternativas botánicas de manejo de estas plagas, se estableció este experimento en el que se evaluaron productos botánicos (chile + ajo + jabón, madero negro, crisantemo, extracto alcohólico + chile, extracto alcohólico + chile + ajo) usados por productores y que existieran en su mayoría en la localidad o de manera accesible al productor en el mercado, sin recurrir a productos químicos. Mediante esto nos fue posible conocer el efecto que tienen los productos sobre el complejo mosca blancaGeminivirus y Halticus sp y otros insectos plagas asociados al cultivo del tomate, determinar cuál o cuáles de estas alternativas presenta mayor efectividad en el manejo de estas plagas y por tanto mayor rentabilidad económica, permitiendo a los productores un uso adecuado de pesticidas menos contaminante con el medio ambiente y la salud, finalmente se propone conocer los biotipos de mosca blanca y tipos de virus presentes en Tisma, Masaya.

\section{MATERIALES Y MÉTODOS}

El estudio se realizó en el municipio de Tisma, departamento de Masaya en la finca El chagüite propiedad de la Productora Elizabeth González en el período comprendido de diciembre 2013 a marzo 2014. Tisma está ubicado a $39 \mathrm{~km}$ y al noroeste de la capital Managua, entre las coordenadas $12^{\circ} 04^{\prime}$ de latitud norte y $86^{\circ} 01^{\prime}$ de longitud oeste y posee una superficie de $126.17 \mathrm{~km}^{2}$ con una población de 10681 habitantes, donde el $71 \%$ de la población es rural y el $29 \%$ es urbana. Tisma se encuentra a una altitud de $50 \mathrm{msnm}$, presenta un clima que se caracteriza por ser tropical de sabana, con temperaturas promedios de $27.5^{\circ} \mathrm{C}$ y con precipitaciones pluviales anuales que oscilan entre los 1200 y 1400 mm (AMUNIC, 2005).

Establecimiento del ensayo. Antes del establecimiento del ensayo en el campo, se estableció un semillero de tomate el 21 de octubre del 2013, esto se llevó a cabo mediante la utilización de bandejas de polietileno con 96 y 105 celdas cada una, donde se depositaron las semillas, el semillero se realizó bajo condiciones de microinvernadero. El sustrato utilizado fue $50 \%$ tallo de coco molido y $50 \%$ humus de lombriz en proporción.

El híbrido utilizado fue Shanty el cual posee alta tolerancia al TYLCV (Tomato Yellow Leaf Curl Virus) y un potencial de rendimiento muy alto. Shanty es un tomate grande afrutado cuyo peso oscila entre 120 y 150 gramos de color rojo intenso con hombros claros, de larga vida de anaquel. Este híbrido es vigoroso para cultivo de estacas y de buena producción adaptada al aire libre. Para el manejo de enfermedades fungosas en el microinvernadero se utilizaron sulfato de cobre pentahidratado (Phyton $\AA)$, Bencimidazol

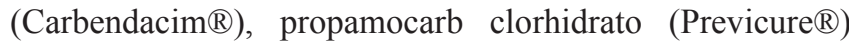
en el caso de fungicidas/bactericidas se usó Trifloxystrobin (Revancha $\left.{ }^{\circledR}\right)$, y para el manejo de enfermedades bacterianas se utilizó Estreptomicina (Cuprimicyn $®)$, Azoxistrobin (Amistar $\left.{ }^{\circledR}\right)$, Estreptomicina+ Oxitetraciclina (Agrimicyn $®$ ) y Mefenoxam (Ridomil®). También se utilizó Multifit como enraizador, además de fósforo y micro elementos. 
Diseño experimental. El estudio se estableció bajo un diseño de BCA (bloques completos al azar), con cuatro repeticiones por tratamiento, donde se evaluaron cinco tratamientos botánicos y un testigo absoluto, para el manejo de mosca blanca y otros insectos plagas. Se utilizó una parcela de forma rectangular cuyas dimensiones fueron de tres metros de largo y 2.85 metros de ancho para un área de $8.55 \mathrm{~m} 2$. Para un total de área por bloque de $51.3 \mathrm{~m} 2$ y un área total del experimento de $368 \mathrm{~m} 2$. Se utilizaron distancias de siembra entre plantas de 0.5 metros y entre surcos de un metro, cada parcela está compuesta por tres surcos y cada surco estaba conformado por un total de seis plantas para un total de 18 plantas por parcela, dejando una separación entre parcela de un metro.

Muestreo de insectos. Para determinar las poblaciones de insectos por planta, se realizaron muestreos semanales a las siete de la mañana, se revisaron 10 plantas al azar por unidad experimental, los datos se anotaron en una hoja de muestreo. Dentro del bloque fueron muestreadas las seis unidades experimentales, para un total de 60 plantas por bloque, tomando en cuenta que eran cuatrpo bloques se muestrearon 240 plantas en todo el experimento.

Aplicación de productos. Las aplicaciones de los productos se realizaron en base a los datos obtenidos en el muestreo, utilizando un nivel crítico poblacional de 0.5 insectos por planta de tomate como parámetro de decisión para aplicar el tratamiento, debido a que por encima de este nivel crítico las plagas alcanzan el nivel de daño económico.

\section{Tratamientos botánicos}

Tratamiento 1. Chile + ajo + Jabón (Detergente). El ajo contiene compuestos de azufre (tiosulfatos) que sobre excitan el sistema nervioso de insectos y ácaros produciendo irritación, desorientación y repelencia. El chile y el ajo se utilizan como insecticidas de contacto (Jiménez-Martínez y Varela 2012). El jabón tiene una función de adherente y su forma de acción es de contacto, las sales potásicas de ácidos grasos penetran el cuerpo de los insectos por ruptura de la cutícula y de las membranas; distorsionando la permeabilidad normal y la fisiología celular, provocando el derrame de líquidos corporales y la muerte (Gómez y Vasquéz, 2011).

Tratamiento 2. Madero negro. Causa disminución de la actividad fagodisuasiva sobre los adultos de B. tabaci en condiciones de invernadero (Lanuza y Rizo, 2012). Se utiliza para el control de mosca blanca y pulgones (áfidos) (JiménezMartínez y Varela, 2012).

Tratamiento 3. Crisantemo. Su compuesto activo son las piretrinas, estas no son residuales porque la luz y el aire las degradan en cuestión de horas. Son altamente tóxicas y repelentes para una gran diversidad de insectos y artrópodos.
Actúan afectando el sistema nervioso central de los insectos causando parálisis inmediata (Jiménez-Martínez y Varela, 2012).

Tratamiento 4. Extracto alcohólico (alcohol isopropílico) + chile. El extracto alcohólico tiene un efecto de contacto. Actúa afectando el sistema respiratorio de los insectos y su sistema nervioso. Ejerce una función bactericida, bacteriostática, fungicida y también actúa sobre algunos virus. Además sirve como solvente para aceites y alcaloides. La capsicina es un alcaloide presente en el chile, es el componente irritante y repelente del extracto. Este alcaloide es resistente al calor y la luz solar.

Tratamiento 5. Extracto alcohólico (alcohol isopropílico) + chile + ajo. El compuesto tiene un efecto de contacto y a la vez repele, desorienta e irrita a las plagas debido a la presencia de la capsicina y tiosulfatos. Así como también el efecto del alcohol de contacto y su función antiséptica y como solvente.

Testigo. En este tratamiento se aplicó solamente agua asperjada con la bomba de mochila para ahogar a los insectos plaga.

\section{Variables evaluadas}

Número de moscas blancas por planta. Se realizaron muestreos de mosca blanca (Bemisia tabaci) a partir de los siete ddt (días después del trasplante), realizándose 10 registros a partir de esta fecha. Para la obtención de los datos se tomaron 10 plantas al azar por parcela, revisándose el envés de las hojas. Las aplicaciones de los tratamientos se realizaron cuando se encontró un nivel poblacional promedio de 0.5 mosca blanca por planta.

Severidad del daño de virosis. La severidad es el porcentaje de tejido dañado o afectado de una planta en un tiempo determinado. Para obtener el grado de severidad ocasionado por mosca blanca se utilizó la escala de severidad, propuesta por Jiménez-Martínez et al., (2010), en la cual el grado cero corresponde a cero por ciento, no hay síntomas; grado uno, corresponde a $25 \%$, débil mosaico y rizado en la lámina foliar de las hojas nuevas; grado dos, corresponde a $50 \%$, mosaico y rizado de las hojas generalizado; grado tres, corresponde a $75 \%$, mosaico, rizado y deformación de hojas y ramas; y grado cuatro, corresponde a $100 \%$, enanismo y deformación severa.

Para obtener el porcentaje de severidad se utilizó la fórmula planteada por Vanderplank (1963). $\mathrm{S}=\sum \mathrm{I} / \mathrm{N}(\mathrm{VM}) \times 100$, Donde: $\mathrm{S}=$ Porcentaje de severidad, $\sum \mathrm{i}=$ Sumatoria de valores observados, $\mathrm{N}=$ Número de plantas muestreadas y $\mathrm{VM}=$ Valor máximo de la escala. 
Determinación del biotipo de mosca blanca. Se colectaron 30 moscas blancas dentro de la parcela. Estas muestras fueron enviadas al laboratorio de Tucson, Arizona para la determinación del Biotipo de mosca blanca encontrada en la localidad de Tisma Masaya. Esto se realizó con el fin de determinar el tipo de plaga y cómo este incide en la afectación del cultivo de tomate.

Diagnóstico de los tipos de virus presente en el cultivo de tomate. Se colectaron tres hojas de la planta de tomate durante la fase de fructificación con síntomas de virosis, luego fueron sumergidas en dos frascos de glicerol. Esto permitió que el tejido se mantuviera en buen estado para ser analizado. Posteriormente se enviaron las muestras al laboratorio de Tucson, Arizona para diagnosticar cuales virus afectaban al cultivo de tomate en Tisma, Masaya.

Número de Halticus sp por planta. Se realizaron muestreos de Halticus sp por planta en 10 fechas revisando el haz y envés de las hojas. Los datos se anotaron en una hoja de muestreo. Las aplicaciones de los tratamientos se realizaron cuando se encontró un nivel poblacional promedio de 0.5 Halticus sp por planta.

Rendimiento de tomate. El rendimiento de los tratamientos, se determinó una vez que se cosechó, realizando dos a tres pesajes por semana por cada tratamiento usando una pesa de balanza en el lugar de estudio. El producto fue comercializado por el productor en el mercado de Masaya.

Análisis económico. Se realizó un análisis económicos con la metodología del CIMMYT (1998), con el propósito de determinar los tratamientos con mejor retorno económico, los mejores tratamientos recomendados deben ajustarse a los objetivos y circunstancias de los productores (Alemán, 2004).

Análisis de dominancia. Este análisis de dominancia se efectuó ordenando los costos variables de cada tratamiento de menores a mayores. Se dice que un tratamiento es dominado cuando sus beneficios netos son menores o iguales a los de un tratamiento que tiene costos que varían más bajo.

Tasa de retorno marginal (TRM). Es un procedimiento que se utiliza para calcular las tasas de retorno marginal entre los tratamientos no dominados comenzando con el tratamiento de menor costo y en escala ascendente. Se calculó mediante la fórmula:

$\mathrm{TRM}=((\mathrm{BN} 2-\mathrm{BN} 1) /(\mathrm{CV} 2-\mathrm{CV} 1)) * 100$, donde $\mathrm{BN}$ es beneficio neto y $\mathrm{CV}$ es costo a variables.

Análisis de datos. Una vez recolectado los datos se ordenaron por variable y por tratamiento para luego realizar un análisis de varianza. A los promedios se les realizó una comparación por medio de la prueba de separación de medias de Tukey con un nivel de significancia de $\mathrm{p} \leq 0.05$. Se utilizó el programa estadístico SAS (SAS, 2003).

\section{RESULTADOS Y DISCUSIÓN}

El análisis de varianza, indica que existe diferencia significativa $(p=0.0001)$ entre los tratamientos, donde el tratamiento Extracto Alcohólico + Chile + Ajo presenta el menor número de moscas blancas por planta seguido del Chile + Ajo + Jabón y Extracto Alcohólico + Chile (cuadro 2). Es importante observar que se registraron altas poblaciones en comparación con estudios anteriores donde se reporta como promedio más bajo 2.35 moscas blancas por planta (Lanuza y Rizo, 2012) en comparación con 9.62 en este estudio. La mosca blanca Bemisia tabaci (Gennadius) fue descrita hace más de 100 años como una plaga de la patata en Grecia y desde entonces se ha convertido en una de las plagas más importantes que afectan a la agricultura mundial; Bemisia tabaci constituye una de las plagas más importantes y con mayor carácter invasivo y dañino en los cultivos alrededor de todo el mundo. La mosca blanca posee una amplia plasticidad genética, por lo que ha desarrollado biotipos que poseen una mayor agresividad que la especie autóctona (biotipo A). El biotipo B es el que ha producido más pérdidas y daños en América Latina (Jiménez-Martínez, 2007).

Cuadro 1. Comparación estadística de las poblaciones de Bemisia tabaci, entre diciembre de 2013 y marzo de 2014, Tisma, Masaya

\begin{tabular}{lc}
\hline Tratamientos & Medias $\pm \mathrm{ES}$ \\
\hline Extracto alcohólico+Chile+Ajo & $9.62 \pm 0.40 \mathrm{a}$ \\
Chile+Ajo+Jabón & $9.90 \pm 0.40 \mathrm{a}$ \\
Extracto alcohólico+Chile & $10.60 \pm 0.39 \mathrm{ab}$ \\
Madero Negro & $11.00 \pm 0.39 \mathrm{ab}$ \\
Crisantemo & $11.90 \pm 0.40 \mathrm{~b}$ \\
Testigo & $11.93 \pm 0.40 \mathrm{~b}$ \\
\hline $\mathrm{N}$ & 2157 \\
\hline $\mathrm{CV}$ & 69.29 \\
\hline (F; $d f ; \mathrm{P})$ & $6.04,2151,0.0001$ \\
\hline Tukey $=(p:$ 0.0001), ES: Error Estándar, CV: Coeficiente de \\
variación, N: Número de datos utilizados en el análisis, F: \\
Fischer calculado, $d f:$ Grados de libertad del error, $p:$ \\
Probabilidad según Tukey.
\end{tabular}

Severidad del daño de virosis transmitido por B. tabaci. Se comparó la severidad del daño de virosis transmitido por mosca blanca a los $100 \mathrm{ddt}$ (figura 1), se observó que los mayores porcentajes de severidad del daño de virosis lo presentaron los tratamientos crisantemo con un $80 \%$ de severidad, seguido del tratamiento madero negro con un $75 \%$ de severidad, en cambio los menores porcentajes de severidad de daño de virosis se registyran en los con extracto alcohólico + chile + ajo y extracto alcohólico + chile con un $62 \%$ y $63 \%$ respectivamente. Los síntomas de virosis transmitidos 
por B. tabaci se caracteriza por un amarillamiento general de la parte afectada, al que se suma un enanismo marcado, seguidamente de un arrugamiento severo de las hojas terminales de la planta, acompañado de un enanismo severo (Hilje, 1996).

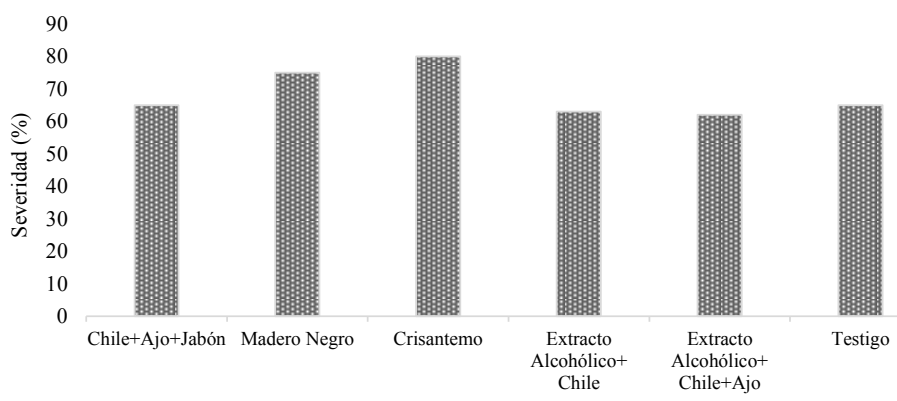

Figura 1. Porcentaje de severidad del daño de virosis transmitido por mosca blanca 100 días según tratamiento.

En el cuadro 2, se presentan los virus que se identificaron en la plantación de Tomate en Tisma, se encontró virus del mosaico dorado de la chiltoma y virus del rizado de la hoja en tomate. Estos son resultados de acuerdo a análisis de Begomovirus realizados el 10 de junio de 2014 en el laboratorio de Virologia de la Universidad de Tucson, Arizona bajo la supervisión y dirección de la Dra. Judith Brown. En los resultados se muestra que en las tres muestras enviadas se dio la presencia de virus en los resultados de la secuenciación de genes, en los tres resultados se mostró la presencia de los dos virus con un porcentaje de por encima del $97 \%$ de afectación del tejido, esto según los datos de secuenciación de nucleótidos y de proteínas del GenBank de Tucson, Arizona. Además se enviaron muestras de moscas blancas para identificar su genotipo en donde se encontró que el $33.33 \%$ eran del biotipo autóctono (A) el otro $66.66 \%$ era de un biotipo más agresivo (B).

Se comparó la ocurrencia poblacional de Halticus $s p$ desde diciembre 13 del 2013 hasta febrero 14 del 2014 (cuadro 3). El análisis de varianza realizado de la fluctuación poblacional de Halticus $s p$ indica que existen diferencias significativas $(p=0.0002)$ entre los tratamientos, donde el tratamiento madero negro presentó los menores promedios con 4.07 Halticus $s p$ por planta, seguido el tratamiento extracto alcohólico + chile con 4.40 Halticus sp por planta en comparación con el testigo que obtuvo 4.49 Halticus sp por planta.

Cuadro 3. Comparación estadística de la población de Halticus sp, en el período comprendido entre diciembre 2013 a febrero 2014, Tisma, Masaya

\begin{tabular}{lc}
\hline Tratamientos evaluados & Medias $\pm \mathrm{ES}$ \\
\hline Madero Negro & $4.07 \pm 0.19 \mathrm{a}$ \\
Extracto alcohólico+Chile & $4.40 \pm 0.17 \mathrm{ab}$ \\
Testigo & $4.49 \pm 0.17 \mathrm{ab}$ \\
Crisantemo & $4.66 \pm 0.17 \mathrm{~b}$ \\
Extracto alcohólico+Chile+Ajo & $4.79 \pm 0.17 \mathrm{bc}$ \\
Chile+Ajo+Jabón & $5.25 \pm 0.18 \mathrm{c}$ \\
\hline $\mathrm{N}$ & 1645 \\
\hline $\mathrm{CV}$ & 62.42 \\
\hline (F; $d f ; \mathrm{P})$ & $4.81,1639,0.0002$ \\
\hline
\end{tabular}

ES: Error Estándar, CV: Coeficiente de variación, N: Número de datos utilizados en el análisis, F: Fischer calculado, $d f$ : Grados de libertad del error, P: Probabilidad según Tukey.

Rendimiento total $\left(\mathrm{kg} \mathrm{ha}^{-1}\right)$ de tomate. Se comparó el rendimiento total de las parcelas de tomate en el período comprendido de diciembre 2013 a marzo 2014 (figura, 2). Los rendimientos totales obtenidos muestran que el tratamiento que obtuvo el mayor rendimiento fue la parcela tratada con extracto alcohólico + chile + ajo con 41622.22 $\mathrm{kg} \mathrm{ha}^{-1}$. Los tratamientos tratados con chile + ajo + jabón, el testigo y extracto alcohólico + chile obtuvieron rendimientos de $36737.14 \mathrm{~kg} \mathrm{ha}^{-1}, 31182.11$ y $28668.30 \mathrm{~kg} \mathrm{ha}^{-1}$ respectivamente, en cambio los tratamientos madero negro y crisantemo obtuvieron los menores rendimientos con 25 423.06 y $23365.05 \mathrm{~kg} \mathrm{ha}^{-1}$ respectivamente. Los tratamientos evaluados en este estudio reflejan que extracto alcohólico + chile + ajo fue el tratamiento que obtuvo

\begin{tabular}{|c|c|c|c|}
\hline $\begin{array}{l}\text { Condición de } \\
\text { la muestra }\end{array}$ & Comentarios & Begomovirus & $\begin{array}{l}\text { Resultados de la secuenciación } \\
\text { en el GenBank }\end{array}$ \\
\hline Buena & $\begin{array}{l}\text { Tejido en glicerol, todos los tubos } \\
\text { igualmente marcados }\end{array}$ & $\begin{array}{l}\text { Positivo } \\
\text { Positivo }\end{array}$ & $\begin{array}{l}\text { Virus del mosaico dorado de la } \\
\text { chiltoma } 98 \% \text { de identidad } \\
\text { Virus del enrollamiento severo } \\
\text { del tomate } 97 \% \text { de identidad }\end{array}$ \\
\hline Buena & $\begin{array}{l}\text { Tejido en glicerol, todos los tubos } \\
\text { igualmente marcados }\end{array}$ & $\begin{array}{l}\text { Positivo } \\
\text { Positivo }\end{array}$ & $\begin{array}{l}\text { Virus del enrollamiento severo } \\
\text { del tomate } 97 \% \text { de identidad } \\
\text { Virus del enrollamiento severo } \\
\text { del tomate } 98 \% \text { de identidad }\end{array}$ \\
\hline Buena & $\begin{array}{l}\text { Tejido en glicerol, todos los tubos } \\
\text { igualmente marcados }\end{array}$ & $\begin{array}{l}\text { Positivo } \\
\text { Positivo }\end{array}$ & $\begin{array}{l}\text { Virus del enrollamiento severo } \\
\text { del tomate } 99 \% \text { de identidad } \\
\text { Virus del enrollamiento severo } \\
\text { del tomate } 96 \% \text { de identidad }\end{array}$ \\
\hline
\end{tabular}
el mayor rendimiento en $\mathrm{kg} \mathrm{ha}^{-1}$ con respecto a los demás, seguido de chile + ajo + jabón, El testigo, extracto alcohólico + chile y los tratamientos que presentaron menor rendimiento fueron madero negro $\mathrm{y}$ crisantemo. 
Presupuesto parcial. El análisis del presupuesto parcial (cuadro 4) realizado, determinó que los mayores costos variables se obtuvieron con los tratamientos extracto alcohólico + chile + ajo, extracto alcohólico + chile y crisantemo con $486.93,455.72$ y 452.79 USD ha- 1 , los de menor costos variables fueron madero negro, chile + ajo + jabón y testigo con $377.68,355.65$ y 268.44 USD ha 1. El tratamiento que obtuvo el mayor beneficio neto fue extracto alcohólico + chile + ajo, en cambio el tratamiento que presentó los menores beneficios netos fue crisantemo.
Análisis de la tasa de retorno marginal. El análisis de la tasa de retorno marginal (cuadro 6) refleja que para el control de mosca blanca el mejor tratamiento es el chile + ajo + jabón ya que por cada dólar invertido el agricultor obtiene una tasa de retorno marginal de $1476 \%$, es decir que por cada dólar

Cuadro 5. Análisis de dominancia

\begin{tabular}{lcll}
\hline \multicolumn{1}{c}{ Análisis de dominancia } & CV & \multicolumn{1}{c}{ BN } & Dominancia \\
\hline Testigo & 268.44 & 2396.22 & No dominado \\
Chile+ajo+jabón & 355.05 & 3674.45 & No dominado \\
Madero negro & 377.68 & 872.01 & Dominado \\
Crisantemo & 452.59 & 291.46 & Dominado \\
Extracto alcohólico+chile & 455.72 & 1591.32 & No dominado \\
Extracto alcohólico+chile+ajo & 486.93 & 4742.80 & No dominado \\
\hline
\end{tabular}

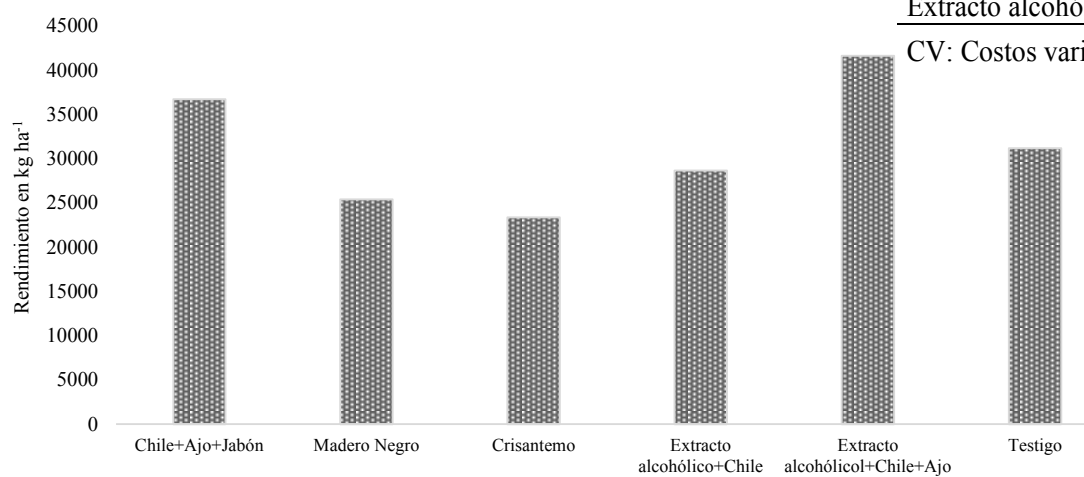

invertido se recupera dicho dólar y 14.76 dólares adicionales, siendo estos beneficios mayores que los que aportan los otros tratamientos. Si se usa extracto alcohólico + chile + ajo para el control de la mosca blanca, por cada dólar invertido se obtiene una tasa de retorno marginal de $810 \%$ lo cual equivale a 8.10 dólares adicionales una vez recuperado el dólar invertido.

Figura 2. Rendimiento total del tomate en kg ha-1 según tratamiento, Tisma, Masaya.

Análisis de dominancia. El resultado del análisis de dominancia (cuadro 5) indica que los tratamientos madero negro, extracto alcohólico + chile y crisantemo resultaron ser dominados por los tratamientos testigo, chile + ajo + jabón, extracto alcohólico + chile

Cuadro 6. Análisis de la tasa de retorno marginal

\begin{tabular}{lccccc}
\hline Tratamiento & $\begin{array}{c}\text { Costo } \\
\text { variable }\end{array}$ & $\begin{array}{c}\text { Costo } \\
\text { Marginal }\end{array}$ & $\begin{array}{c}\text { Beneficio } \\
\text { Neto }\end{array}$ & $\begin{array}{c}\text { Beneficio } \\
\text { Marginal }\end{array}$ & $\begin{array}{c}\text { Tasa de retorno } \\
\text { marginal \% }\end{array}$ \\
\hline Testigo & 268.44 & & 2396.22 & & \\
Chile+ajo+jabón & 355.05 & 86.62 & 3674.45 & 1278.22 & $1476 \%$ \\
Extracto alcohólico+chile+ajo & 486.93 & 131.88 & 4742.80 & 1068.36 & $810 \%$ \\
\hline
\end{tabular}
y extracto alcohólico + chile + ajo. Por lo tanto no fueron incluidos en el análisis de la tasa de retorno marginal.

Cuadro 4. Presupuesto parcial de los tratamientos evaluados

\begin{tabular}{|c|c|c|c|c|c|c|}
\hline Concepto & $\begin{array}{l}\text { Chile+Ajo } \\
\text { +Jabón }\end{array}$ & $\begin{array}{l}\text { Madero } \\
\text { negro }\end{array}$ & Crisantemo & $\begin{array}{c}\text { Extracto } \\
\text { alcohólico+chile }\end{array}$ & $\begin{array}{c}\text { Extracto } \\
\text { alcohólicol+ } \\
\text { chile+Ajo }\end{array}$ & Testigo \\
\hline Rendimiento ( $\left.\mathrm{kg} \mathrm{ha}^{-1}\right)$ & 40819.05 & 28247.85 & 25961.16 & 31853.66 & 46246.91 & 34646.79 \\
\hline $\begin{array}{l}\text { Rendimiento }\left(\mathrm{kg} \mathrm{ha}^{-1}\right) \\
\text { ajustado al 25\% }\end{array}$ & 30614.28 & 21185.89 & 19470.87 & 23890.25 & 34685.18 & 25985.09 \\
\hline Precio de campo & 0.29 & 0.29 & 0.29 & 0.29 & 0.29 & 0.29 \\
\hline Ingreso Bruto & 8878.14 & 6143.91 & 5646.55 & 6928.17 & 10058.70 & 7535.68 \\
\hline Total de C.F. USD ha-1 & 4996.60 & 4996.60 & 4996.60 & 4996.60 & 4996.60 & 4996.60 \\
\hline Total de CV USD ha-1 & 355.05 & 377.68 & 452.59 & 455.72 & 486.93 & 268.44 \\
\hline Beneficio neto USD ha-1 & 3674.45 & 872.01 & 291.46 & 1591.32 & 4742.80 & 2396.22 \\
\hline
\end{tabular}

Precio del producto al momento de la cosecha (0.29 USD kg-1). 


\section{CONCLUSIONES}

El tratamiento que resultó con menor promedio de moscas blancasy menor porcentaje de severidad a los cien días después de trasplante fue el extracto alcohólico + chile + ajo.

El tratamiento madero negro fue el que presentó mayor efectividad en el manejo de poblaciones de Halticus $s p$.

El tratamiento que obtuvo el mejor rendimiento en $\mathrm{kg} \mathrm{ha}^{-1}$ fue el extracto alcohólico+chile+ajo seguido por el tratamiento chile+ajo+jabon.

El análisis de dominancia demuestra que los tratamientos extracto alcohólico + chile + ajo, testigo y chile + ajo + jabón resultaron no dominados, siendo estos los mejores tratamientos viables económicamente.

El análisis de la tasa de retorno marginal indica que el tratamiento chile + ajo + jabón tiene una tasa de retorno marginal de $1476 \%$ lo que quiere decir que por cada dólar invertido se obtiene una ganancia de 14.76 dólares netos adicionales y si usa extracto alcohólico + chile + ajo se obtiene una tasa de retorno de $810 \%$ es decir una ganancia de 8.10 dólares adicionales.

\section{AGRADECIMIENTO}

Los autores de esta investigación agradecen a la Sra. Elizabeth González y al Sr. Anuar González, productores de Tisma, Masaya por su apoyo con esta investigación, a la Universidad Nacional Agraria (UNA) por su apoyo económico, a la Dra. Judith K. Brown de la Universidad de Tucson, Arizona por apoyarnos con los análisis de laboratorio de los virus y los genotipos de mosca blanca, al Dr. Paul Vincelly de la Universidad de Kentucky por su apoyo en el diseño de la investigación y por contactarnos con la Dra. Brown.

\section{REFERENCIAS BIBLIOGRÁFICAS}

Alemán, F. 2004. Valoración económica en experimentación agrícola. In Manual de investigación agronómica: con énfasis en ciencias de las malezas. Managua, NI. $189 \mathrm{p}$.

Álvarez, D; Sánchez, K. 2014. Mosca blanca (Bemisia tabaci): Generalidades y biotipos (en línea). Consultado el 6 oct. 2014. Disponible en http://www.tec-digital.itcr.ac.cr/file/6323410/Bemisia tabaci.pdf

AMUNIC (Asociación de Municipios de Nicaragua). 2005. Municipios: Caracterización de municipios de Masaya (en línea). Consultado el 9 de agos. 2010. Disponible en http//www.amunic.org/

CATIE (Centro Agronómico Tropical de Investigación y Enseñanza, CR). 1990. Guía para el manejo integrado de plagas para el tomate. Proyecto regional MIP. (Serie Técnica. Informe Técnico/ CATIE; n 151). Turrialba, CR. 138 p.

CYMMYT (Centro Internacional para el Mejoramiento del Maíz y el Trigo, MX). 1998. La formulación de recomendaciones a partir de datos económicos. Un manual metodológico de evaluación económica. 79 p.

Gómez, D; Vásquez, M. 2011. Manejo de plagas (en línea). Tegucigalpa, HN. Consultado 19 oct. 2014. Disponible en http://www. sitrural.cl//wp-content/plugins/downloads-manager/upload/plagas.pdf.

Hilje, L. 1996. Metodología para el estudio y manejo de moscas blancas y geminivirus. CATIE, Turrialba, CR. 133 p.

INTA (Instituto Nicaragüense de Tecnología Agropecuaria). 2004. Introducción. In guía técnica sobre el manejo integrado de plagas en el cultivo del tomate. Managua, NI. p. 3

Jarquín Palacios, DA. 2004. Evaluación de cuatro líneas de tomate (Licopersicum sculentum), basado en el complejo mosca blanca (Bemisia tabaci)-geminivirus, en la comunidad de Aponpúa, Potosí, Rivas, Nicaragua. Tesis. MSc. Sistemas integrales de producción agropecuaria en el trópico, con énfasis e recursos naturales. Managua, NI. Universidad Autónoma de BarcelonaUNA. $73 \mathrm{p}$.

Jiménez-Martínez, E. 2007. Guía de manejo integrado de mosca blanca y virus en Nicaragua. Universidad Nacional Agraria. Managua, NI. $30 \mathrm{p}$.

Jiménez-Martínez, E; Gutierrez, W; Gonzalez, C. 2010. Evaluación de cuatro variedades de tomate industrial (Lycopersicum esculentum, Mill) en el rendimiento y tolerancia al complejo mosca blanca (Bemisia tabaci, Gennadius)-Geminivirus, La Calera 10(15):5-15.

Jiménez-Martínez, E; Varela, G. 2012. Compendio manejo integrado de plagas. Universidad Nacional Agraria. Managua, NI. 64 p.

Lanuza, E; Rizo, E. 2012. Evaluación de productos botánicos y químicos sobre el complejo mosca blanca (Bemisia tabaco Gennadius)-Geminivirus en el cultivo de tomate (Solanum esculentum, Mill.), en Tisma-Masaya. Tesis Ing. ISPAF. Universidad Nacional Agraria, Facultad de Agronomía. Managua, NI. 38 p.

MIFIC (Ministerio de Fomento, Industria y Comercio, NI). 2007. Ficha del tomate. Managua, NI. 14 p.

Richmond, F. 2012. Plagas comunes en cultivos hidropónicos. In PRONAP (Programa Nacional de Producción Agrícola bajo ambientes protegidos). 2012. Boletín del programa nacional sectorial de producción agrícola bajo ambientes protegidos. Sector agro alimentario 6(35):4-9.

SAS Institute, 2003. University of Nebraska. Cary, NC, USA.V.91.

Vanderplank, EJ. 1963. Plants diseases: Epidemiology and control. New York. Academia press. 69 p. 